\title{
Cortical Neurodynamics of Inhibitory Control
}

\author{
Kai Hwang, ${ }^{1,2,3}$ Avniel S. Ghuman, ${ }^{3,4}$ Dara S. Manoach, ${ }^{5,6}$ Stephanie R. Jones, ${ }^{6,7}$ and Beatriz Luna ${ }^{1,2,3}$ \\ ${ }^{1}$ Department of Psychiatry and ${ }^{2}$ Department of Psychology, University of Pittsburgh, Pittsburgh, Pennsylvania 15213 , ${ }^{3}$ Center for the Neural Basis of \\ Cognition, Carnegie Mellon University and University of Pittsburgh, Pittsburgh, Pennsylvania, 15213, ${ }^{4}$ Department of Neurological Surgery, University of \\ Pittsburgh, Pittsburgh, Pennsylvania 15213, ${ }^{5}$ Department of Psychiatry, Massachusetts General Hospital, Harvard Medical School, Boston, Massachusetts \\ 02114, ${ }^{6}$ Athinoula A. Martinos Center for Biomedical Imaging, Charlestown, Massachusetts 02129, and ${ }^{7}$ Department of Neuroscience, Brown University, \\ Providence, Rhode Island 02912
}

The ability to inhibit prepotent responses is critical for successful goal-directed behaviors. To investigate the neural basis of inhibitory control, we conducted a magnetoencephalography study where human participants performed the antisaccade task. Results indicated that neural oscillations in the prefrontal cortex (PFC) showed significant task modulations in preparation to suppress saccades. Before successfully inhibiting a saccade, beta-band power $(18-38 \mathrm{~Hz})$ in the lateral PFC and alpha-band power $(10-18 \mathrm{~Hz})$ in the frontal eye field (FEF) increased. Trial-by-trial prestimulus FEF alpha-band power predicted successful saccadic inhibition. Further, inhibitory control enhanced cross-frequency amplitude coupling between PFC beta-band $(18-38 \mathrm{~Hz})$ activity and FEF alpha-band activity, and the coupling appeared to be initiated by the PFC. Our results suggest a generalized mechanism for top-down inhibitory control: prefrontal beta-band activity initiates alpha-band activity for functional inhibition of the effector and/or sensory system.

Key words: antisaccade; inhibitory control; neural oscillations; prefrontal cortex

\section{Introduction}

The ability to suppress prepotent or contextually inappropriate responses is critical for flexible goal-directed behaviors. Tasks that require inhibiting motor responses are supported by cortical and subcortical circuitries, including prefrontal regions such as the dorsal lateral prefrontal cortex (DLPFC; Menon et al., 2001; DeSouza et al., 2003) and the ventral lateral prefrontal cortex (VLPFC; Aron et al., 2007; Chikazoe et al., 2007). The antisaccade (AS) task (Hallett, 1978; Munoz and Everling, 2004), an oculomotor inhibitory control task that requires participants to inhibit prepotent saccades, also recruits the putative human frontal eye field (FEF; Connolly et al., 2002; DeSouza et al., 2003). Frontal cortical activity likely reflects a myriad of processes, including representation of task goals and exerting top-down control signals to inhibit unwanted processes (Criaud and Boulinguez, 2013). However, relatively little is known about how prefrontal circuit instantiates and integrates these complex and dynamic cognitive processes.

One possibility is that synchronous neural oscillations provide a flexible coding and processing scheme for diverse processes

Received Nov. 20, 2013; revised May 29, 2014; accepted June 6, 2014.

Author contributions: K.H. and B.L. designed research; K.H. performed research; A.S.G., D.S.M., and S.R.J. contributed unpublished reagents/analytic tools; K.H. analyzed data; K.H., A.S.G., D.S.M., S.R.J., and B.L. wrote the paper.

This work was supported by National Institute of Mental Health Grant R01 MH067924 and the MEG Research Seed Fund from the UPMC-Brain Mapping Center. We thank Soma Chatterji, Natalie Nawarawong, and Amanda Wright for assistance in data collection; TJ Amdurs, Anna Haridis, and Erika Taylor for technical support; Michael Hallquist for statistic consulting; and Chris Moore for comments on this manuscript.

The authors declare no competing financial interests.

Correspondence should be addressed to Kai Hwang, PhD, 3811 0'Hara Street, Loeffler Building, Room 108, University of Pittsburgh, Pittsburgh, PA 15213. E-mail: kah124@pitt.edu.

DOI:10.1523/JNEUROSCI.4889-13.2014

Copyright $\odot 2014$ the authors $\quad 0270-6474 / 14 / 349551-11 \$ 15.00 / 0$
(Canolty and Knight, 2010; Cohen, 2011; Buschman et al., 2012). In support, computational models and neurophysiology studies suggest that oscillatory neurodynamics are signatures of distinct physiological processes that support cognitive functions (Jones et al., 2009; Wang, 2010; Siegel et al., 2012). Recent human electroencephalography (EEG) studies in sensory systems have indicated that the allocation of attention leads to enhanced alphaband $(8-14 \mathrm{~Hz})$ and beta-band $(15-30 \mathrm{~Hz})$ power in the representation of unattended locations, where distractors to task performance may be present (Foxe et al., 1998; Worden et al., 2000; Jones et al., 2010; Banerjee et al., 2011; Belyusar et al., 2013). Neurophysiology studies have further indicated that beta-band activity increased with cognitive effort (Buschman and Miller, 2007; Buschman et al., 2012). In aggregate, these studies predict that the adaptive allocation of alpha-band and/or beta-band oscillatory dynamics may suppress perceptual salience or motor activity in accordance with the behavioral goal (Klimesch et al., 2007; Jensen and Mazaheri, 2010).

To directly test the relationship between oscillatory dynamics and inhibitory control, we conducted a magnetoencephalography (MEG) study where human participants performed intermixed blocks of AS and control prosaccade (PS) trials. Each trial consisted of a "preparatory period" where an instructional cue ("cue") was presented indicating a subsequent AS or PS trial. The cue was followed by an unpredictable peripheral visual stimulus ("target") indicating the saccade direction (for the PS task), or to inhibit and then generate a saccade to the mirror location (for the AS task). Non-human primate studies have shown that correct performance on the AS task requires proactive inhibition of saccade neurons in the FEF before the saccade target is made available (Everling and Munoz, 2000; Munoz and Everling, 2004). Our goal is therefore to compare temporal and spectral aspects of 
preparatory activity between AS and PS trials, isolate the proactive inhibition process initiated according to a behavioral goal (Aron, 2011), and to identify oscillatory neurodynamics specific to preparatory inhibitory control of an anticipated prepotent response.

\section{Materials and Methods}

Participants. Of the 26 adults that participated in the study, we reported data from 20 adults $(10$ male) aged $20-30$ years $(M=26.11$ years, $S D=$ $3.41)$ that successfully completed the study and have a sufficient number of noise-free trials for data analyses. Two participants were dropped because of MEG sensor noise that could not be removed. One participant was dropped because of excessive eye blinks, and three participants were dropped because insufficient number of noise-free trials for analyses. All participants gave written informed consent, and the study was approved by the University of Pittsburgh Institutional Review Board.

Behavioral paradigm. The AS task required participants to suppress a prepotent saccadic response to a peripheral stimulus (target) that appeared in an unpredictable location and instead make a goal-directed saccade to the opposite direction. For the PS task participants were instructed to gaze at the peripheral stimulus. Each trial consisted of a $1.5 \mathrm{~s}$ "preparatory period" where an instructional cue (cue) was presented indicating a subsequent AS or PS trial. A red fixation " $\mathrm{x}$ " instructed participants that an AS trial was to be performed while a green fixation " $x$ " indicated a PS trial. A solid yellow circle target stimulus was then presented for $1.5 \mathrm{~s}$ after the extinction of the cue (the "response period"). The target stimulus (size $\sim 1^{\circ}$, luminance $42.22 \mathrm{~cd} / \mathrm{m}^{2}$ ) was presented on the horizontal meridian at one of four unpredictable eccentricities $( \pm 6.3$ and $\pm 10.6^{\circ}$ from center fixation). A $1.2-1.6 \mathrm{~s}$ jittered white fixation " $\mathrm{x}$ " was presented between trials. We presented AS and PS trials in blocks to minimize task-switching effects that may alter both behavioral performance and neural activity (Akaishi et al., 2010; Lee et al., 2011). The order of task blocks was counterbalanced across participants, and 210 AS trials and 210 PS trials were distributed across eight MEG runs (6 min each). The task was designed using E-PRIME (Psychology Software Tools).

Data acquisition. All MEG data were acquired using an Elekta Neuromag Vectorview MEG system (Elekta Oy) comprising 306 sensors arranged in triplets of two orthogonal planar gradiometers and one magnetometer, distributed to 102 locations. Data were acquired inside a three-layer magnetically shielded room. Visual stimuli were projected to a screen located $1 \mathrm{~m}$ in front of the participant, and the timing accuracy was assured by using a photodiode to measure stimulus delay. MEG data were acquired continuously with a sampling rate of $1000 \mathrm{~Hz}$. Head position relative to the MEG sensors was measured throughout the recording period to allow off-line head movement correction. Two bipolar electrode pairs were used to record vertical and horizontal electrooculogram (EOG) signals to monitor saccades and blinks. EOG data were then scored off-line in MATLAB (MathWorks) using a custom program. Saccades were identified as horizontal eye movements with velocities exceeding 40 degrees/s, with minimum amplitudes of 3 degrees. Given that express saccade could involve distinct subcortical mechanisms that MEG lacks sensitivity to detect (Schiller et al., 1987), we restricted our analyses to regular saccades by excluding both anticipatory and express saccades with initial saccade latencies faster than $130 \mathrm{~ms}$. Structural MRI data were collected at a Siemens $3 \mathrm{~T}$ Tim Trio system scanner using a magnetization-prepared rapid acquisition with gradient echo (MPRAGE) sequence with the following parameters: TR $=2100 \mathrm{~ms}$, TI $=$ $1050 \mathrm{~ms}, \mathrm{TE}=3.43 \mathrm{~ms}, 8^{\circ}$ flip angle, $256 \times 256 \times 192$ acquisition matrices, $\mathrm{FOV}=256 \mathrm{~mm}$, and $1 \mathrm{~mm}$ isotropic voxels.

$M E G$ data processing. MEG sensor data were first manually inspected to reject noisy or flat channels. MEG data were then preprocessed off-line using the temporal signal space separation (TSSS) method (Taulu et al., 2004; Taulu and Hari, 2009). TSSS reduces environmental magnetic artifacts outside the head and sensor artifacts, and performs head movement compensation by aligning sensor level data to a common reference (Nenonen et al., 2012). This head motion correction procedure also provides estimates of head motion relative to sensor coordinates every
$200 \mathrm{~ms}$ - estimates that were used to reject trials contaminated by motion artifacts.

Eye blinks and cardiac and saccade artifacts were then removed using an independent component analysis-based procedure. MEG sensor data were first decomposed into 64 independent components (ICs) using EEGLAB (Delorme and Makeig, 2004) algorithms implemented in the FieldTrip software suite (Oostenveld et al., 2011). The number of ICs (64) was chosen because TSSS internally reduces dimension to 64 components before re-projecting signals back to the sensor space (Taulu et al., 2004; Taulu and Hari, 2009). To identify artifact components, each IC was correlated with electrocardiogram and EOG data. An IC was designated as an artifact if the absolute value of the correlation was 3 SDs higher than the mean of all correlations. For each participant, between two and six artifact components were rejected. The "clean" ICs were then projected back to the sensor space for manual inspection. After the removal of artifacts, sensor data were downsampled to $250 \mathrm{~Hz}$ to improve calculation efficiency. Power line noise was removed using a Fourier transformation of $10 \mathrm{~s}$ long signal window that moved along the full data length and subtracted the $60 \mathrm{~Hz}$ component and its harmonics.

Trials were then inspected for sensor jumps, muscle artifacts, unwanted saccades, and head movement artifacts. Trials with saccades that occurred during the preparatory period or pretrial baseline were excluded. Trials with gradiometer peak-to-peak amplitudes exceeded 3000 $\mathrm{fT} / \mathrm{cm}$ or magnetometer peak-to-peak amplitudes exceeded $10 \mathrm{pT}$ were also excluded. We further rejected trials with sensor displacement $>1$ $\mathrm{mm}$. The amount of head motion was estimated by calculating the frameby-frame sensor displacement relative to the head position (Wehner et al., 2008). Trial rejection resulted in unequal number of trials across conditions and participants, which could lead to biases in estimating measures between conditions (Gross et al., 2013). To maintain a constant signal-to-noise ratio (SNR) across conditions, we fixed the number of trials per condition per participant at 85 correctly performed trials ( $85 \mathrm{AS}$ +85 PS trials). Correct and error trials were analyzed separately to investigate neurocognitive processes related to correct versus incorrect AS responses. For participants that had more than 85 usable correct trials, we selected correctly performed trials randomly. For the logistic regression analyses, all correct and incorrect AS trials (free of artifacts) were coded separately then included into the logistic regression model.

Single-trial MEG sensor data were then projected from the sensors on to the cortical surface to estimate source activities, using the minimumnorm estimates (MNE) procedure. First, the geometry of each participant's cortical surface was reconstructed from the respective structural images using FreeSurfer (Dale et al., 1999; Fischl et al., 1999). The solution space for the source estimation was then constrained to the gray/ white matter boundary, by placing $\sim 3000$ dipoles per hemisphere with 7 $\mathrm{mm}$ spacing. A forward solution for the constructed source space was calculated using a single compartment boundary-element model (Hämäläinen and Sarvas, 1989). The noise covariance matrix was calculated from 700 to $400 \mathrm{~ms}$ before task cues were presented. The noise covariance matrix and the forward solution were then combined to create a linear inverse operator (Dale et al., 2000) to project single-trial MEG sensor data to the cortical surface.

Regions of interest analyses. The goal for our study is to leverage known functional specificity of cortical regions involved in oculomotor control, and reveal previously unknown temporal and spectral aspects of neural signals associated with preparatory inhibitory control. Regions of interest (ROIs) were functionally defined within selected anatomical regions by consulting the relevant literature. These selected structural masks were created using FreeSurfer's automatic parcellation of sulci and gyri (Destrieux et al., 2010) based on each participant's structural MRI. Specifically, we defined the FEF to be located within the precentral sulcus, combining the superior (sFEF) and inferior (iFEF) portions (Luna et al., 1998; Moon et al., 2007; Lee et al., 2011). The superior portion of the precentral sulcus has long been suggested to be the human homolog of monkey FEF (Luna et al., 1998; Curtis, 2011), and human functional imaging studies also found the inferior portion of the precentral sulcus associated with oculomotor control (Luna et al., 1998; Berman et al., 1999; Moon et al., 2007; Lee et al., 2011). The VLPFC was constrained to be within the inferior frontal sulcus, the triangular and the opercular part 
of the inferior frontal gyrus (Aron et al., 2004; Levy and Wagner, 2011), and the DLPFC was defined within the middle frontal sulcus (DeSouza et al., 2003; Badre and D'Esposito, 2009; Koval et al., 2011). The anterior cingulate cortex (ACC) was defined within the anterior and middleanterior part of the cingulate gyrus and sulci (Destrieux et al., 2010), and the supplementary eye field (SEF) was defined within the paracentral lobule and sulcus (Grosbras et al., 1999). ROIs from both hemispheres were selected. Because MEG is relatively insensitive to subcortical sources (Hamalainen et al., 2010), no subcortical ROIs were included.

Within the selected anatomical regions, we selected the top 25\% of dipoles where preparatory oscillatory activities showed robust change from baseline across all conditions, including both correct and incorrect trials. After source localization, single-trial MNE estimates were first averaged across dipoles within each ROI while aligning the sign of current fluctuations across different dipoles. We then spectrally decomposed neural currents at each source by convolving the time-domain signal with a family of complex Morlet wavelets to obtain the power time courses for each trial. For each source location, current estimates $s$ at time $t$ were convolved with the wavelet $G$ centering at frequency $f$ to produce a time frequency representation $\omega$ :

$$
\omega(t, f)=G(t, f) * s(t),
$$

where $f$ stepped from 2 to $60 \mathrm{~Hz}$ by a $2 \mathrm{~Hz}$ increment.

The complex wavelet $G$ was defined as follows:

$$
G(t, f)=\frac{1}{\sqrt{2 \pi f}} \exp \left(\frac{-t^{2}}{2 \sigma^{2}}\right) \exp (i 2 \pi f t)
$$

where $\sigma$ was set to be $7 / 2 \pi f$ to achieve the optimal time-frequency resolution and to ensure the stability of wavelet transformation (TallonBaudry et al., 1997; Ghuman et al., 2011).

For each source location, the time-varying power $P$ for frequency $f$ was obtained with:

$$
P(t, f)=|\omega(t, f)|^{2} .
$$

Briefly, for every trial the time-varying power of all frequencies (2-60 $\mathrm{Hz}$ ) was calculated for all dipole sources within each anatomical structure using Equation 3. Separately for each frequency, the power values were then converted to signal-to-noise estimates by subtracting it from the baseline mean and dividing by the variance of baseline power. Baseline window was defined as $700-400 \mathrm{~ms}$ before the cue presentation. This SNR estimate is analogous to a $z$-score and can be used to identify dipoles where oscillatory activities are robust. We then took the absolute values of $z$-scores, and averaged them within the preparatory period for all trials (AS and PS), regardless of performance. This procedure is akin to deriving an omnibus test statistic for all conditions. Absolute $z$-scores were then further averaged across frequencies $(2-60 \mathrm{~Hz})$. We then identified the dipole with the maximum averaged absolute $z$-score, and drew an ROI around the peak dipole that included 27-30 contiguous dipoles through an iterative spreading operation (Hamalainen, 2010). During this process we noticed that medial sources showed low SNR as indicated by low averaged $z$-scores (Fig. 1), therefore we excluded medial ROIs (ACC and SEF) from further analyses.

Statistical analysis. After ROIs were created for each participant, oscillatory power values were extracted from each ROI and converted to percentage signal changes from baseline power, averaged across trials for each condition, and pooled across participants for statistical analyses using the randomized permutation test.

We performed multilevel, mixed-effect logistic regressions to examine the relationship between trial-by-trial preparatory oscillatory and AS task performance: $P=\exp (a+b x) /(1+\exp (a+b x))$, where $P$ is the probability of correct AS task performance, $a$ is the intercept term, $b$ is the regression coefficient (slope) that quantifies the strength of predictive effect of preparatory oscillatory power for AS task performance, and $x$ is single trial oscillatory power. A positive slope indicates that the stronger the preparatory oscillatory power, the more likely participants will perform correctly on the AS task. Participants were treated as random effect, and intercept and slope terms were treated as fixed effects.
To assess the functional relationship between DLPFC beta-band activity and FEF alpha-band activity, power amplitude time courses were first averaged across trials. Then between ROIs, each frequency's averaged power time course during the preparatory period was correlated with every other frequency's power time course. For each participant, this cross-frequency coupling matrix was calculated separately for each condition (AS and PS). We then contrasted the cross-frequency coupling matrices between AS and PS trials across participants using the randomized permutation test.

To evaluate the strengths of causal influence between DLPFC betaband activity and FEF alpha-band activity, we performed Granger causality analysis (GCA) following the autoregressive modeling approach described by Seth (2010). We first subtracted the mean from each trial's power amplitude time course and divided by the SD. This additional preprocessing step reduced nonstationarity, a requirement for autoregressive modeling. The order of the autoregressive model was set at 80 ms, which was found to show maximum lagged correlation. Granger values were then estimated separately for each trial using time courses from the baseline and the preparatory period. Granger values from the preparatory period were then normalized against the baseline Granger values by subtracting the baseline mean and divided by the baseline SD. Normalized granger values were then averaged across trials per condition and pooled across participants to test for differences between conditions using the randomized permutation test. We focused on interpreting taskrelated modulations in Granger causality values to limit confounds from volume conduction and spurious false positives (Schoffelen and Gross, 2009).

We performed the nonparametric cluster-based permutation test to test for statistical significance and correct for multiple comparisons (Maris and Oostenveld, 2007). Briefly, for each analysis, we permuted the task condition label 1000 times to derive an empirical null distribution of the clustered test statistic that satisfied the null hypothesis of no difference between conditions. The proportion of values in the null distribution that was greater than the original clustered statistic was treated as the corrected significance value.

\section{Results}

\section{Behavioral performance}

As expected, errors for AS trials were significantly higher compared with PS trials (AS: $M \pm \mathrm{SD}=21.9 \pm 9.82 \%$; PS: $2.84 \pm$ $1.99 \%$; paired $t$ test $\left.t_{(19)}=7.95, p<0.001\right)$. Likewise, saccade latency for AS trials was significantly slower compared with PS trials (AS: $320.19 \pm 31.84 \mathrm{~ms}$; PS: $M=235.02 \pm 24.91 \mathrm{~ms}$; paired $t$ test $\left.t_{(19)}=11.92, p<0.001\right)$. To test if participants were able to improve their performances on the AS task through learning, we further compared accuracies and latencies between early and late phases of MEG scanning. We found no significant differences between different quarters (Q1-Q4) of testing (Q1 AS: $M=$ $78.2 \%, \mathrm{SD}=8.72 \%$; Q2 AS: $M=80.1 \%, \mathrm{SD}=9.25 \%$; Q3 AS: $M=79.5 \%, \mathrm{SD}=9.76 \%$; $\mathrm{Q} 4 \mathrm{AS}: M=78.7 \%, \mathrm{SD}=9.55 \%$; repeated measure ANOVA $\left.F_{(3,16)}=0.15, p=0.645\right)$, suggesting that AS task performance has minimal learning effect within a session, allowing us to pool trials altogether for further analyses.

\section{Inhibitory control increases beta-band power in the DLPFC and alpha-band power in the FEF}

Extensive literature has identified several frontal and parietal regions that are associated with inhibitory control (Aron, 2011; Criaud and Boulinguez, 2013). Based on this literature, we selected a priori anatomical structures, and defined ROIs within the selected structures by including dipoles that showed reliable oscillatory activities across frequencies of interest $(2-60 \mathrm{~Hz})$. The following ROIs were included for primary analyses: DLPFC, VLPFC, FEF, and intraparietal sulcus (IPS). MEG is less sensitive to subcortical sources therefore no subcortical regions were included; similarly, medial sources (the ACC and the SEF) were 
omitted because of low SNR in MEG source estimates (Fig. 1). The PS task and the AS task had different cognitive control demands affecting reaction time but resulted in similar saccadic responses. AS versus PS task contrast was used to isolate preparatory inhibitory control processes. We first averaged spectral power of neural activity during the preparatory period, and identified ROIs that showed significant task modulations (Fig. 2). Results indicated that compared with the PS task the AS task induced significantly stronger $18-38 \mathrm{~Hz}$ power in the right DLPFC (Fig. 2 ; permutation test, $p<0.05$ corrected), and significantly stronger power within the putative alpha-band frequency range in three FEF ROIs (the left sFEF: $8-14 \mathrm{~Hz}$, the right iFEF: $6-14 \mathrm{~Hz}$, and the right sFEF: 10-14 Hz; Fig. 2; permutation test, $p<0.05$ corrected). The temporal and spectral profiles of these ROIs were then explored further in subsequent analyses. Because all FEF ROIs showed similar spectral peaks at $\sim 10-12 \mathrm{~Hz}$, the FEF ROIs were then averaged before further statistical tests.

In the right DLPFC, elevated $18-38 \mathrm{~Hz}$ power was found throughout the preparatory period when examining the full time-frequency spectrum (Fig. 3B). Statistical comparison between conditions (AS vs PS) using a randomized permutation test revealed that the AS task showed stronger $18-38 \mathrm{~Hz}$ power during the following time period: from task cue onset to $1088 \mathrm{~ms}$ before target onset, from 840 to $588 \mathrm{~ms}$ before target onset, and from 482 to $184 \mathrm{~ms}$ before target onset (Fig. 3C; permutation test, $p<0.05$ corrected). This effect was not driven by differences in event-related evoked responses (Fig. 3A), as both AS and PS trials showed similar transient evoked peaks immediately subsequent to the cue and target presentations, but showed no differences in evoked amplitudes during the preparatory period. This suggests that the induced oscillatory activities were not phase locked to the instructional cue and could be dissociated from phase-locked evoked responses (Donner and Siegel, 2011). No significant taskrelated modulations in oscillatory power from 18 to $60 \mathrm{~Hz}$ were observed in any other ROIs. The bilateral IPS and the right VLPFC also showed some elevated $14-32 \mathrm{~Hz}$ power for the AS task, but was not statistically significant after controlling for multiple comparisons (Fig. 2).

Averaged spectral power across FEF ROIs showed significantly stronger $10-18 \mathrm{~Hz}$ power during the preparatory period for the AS task compared with the PS task (Fig. $4 B, C$; permutation test, $p<0.05$ corrected). Elevated $10-18 \mathrm{~Hz}$ power was found to sustain throughout the latter half of the preparatory period. Statistical comparison between conditions (AS vs PS) using the randomized permutation test revealed that the AS task showed stronger $10-18 \mathrm{~Hz}$ power near the onset of task cue to $348 \mathrm{~ms}$ after cue onset, as well as during the latter half of the preparatory period, from $1020 \mathrm{~ms}$ after the cue onset till the end of the preparatory period (Fig. $4 C$; permutation test, $p<0.05$ corrected). Similar to the DLPFC, this effect was likely not driven by differences in evoked responses, as no differences were found in evoked event-related time courses between AS and PS trials (Fig. 4A). In addition, unlike evoked responses that showed transient peaks, the $10-18 \mathrm{~Hz}$ power in the FEF showed sustained elevation (Fig. 4B). The bilateral IPS also showed some elevated $10-14 \mathrm{~Hz}$ power, but was not statistically significant (Fig. 2).

To summarize, we observed task-related modulations in $10-18 \mathrm{~Hz}$ power in the FEF and $18-38 \mathrm{~Hz}$ power in the right DLPFC. This dissociation suggests that these effects were specific to those respective regions but not artifacts of volume conduction or global resonance phenomena. Further, because we focused on contrasting signals between AS and PS trials, the effects we observed were unlikely to be solely driven by participants anticipating target appearances, as anticipation effects would be equivalent between conditions. The spectral range we observed is largely consistent with previous observations of cognitively modulated alpha-band rhythm, showing peaks at $\sim 12 \mathrm{~Hz}$, and betaband rhythm, showing peaks at $\sim 20 \mathrm{~Hz}$ (Buschman and Miller, 2007; Swann et al., 2009; Buschman et al., 2012). Hence, for brevity the $10-18 \mathrm{~Hz}$ effect will be summarized as "alpha-band activity" and the $18-38 \mathrm{~Hz}$ effect as "beta-band activity."

\section{Prestimulus alpha-band power predicts AS performance}

Nonhuman primate studies indicate that the preparatory period is crucial for AS task performance (Munoz and Everling, 2004). Specifically, compared with PS trials, preparatory activity of saccade neurons is reduced for AS trials. Furthermore, insufficient reduction of saccade-related activity will lead to incorrect AS performance. Thus, the inhibition of pretarget FEF activity is thought to be important for suppressing reflexive saccades to the target on AS trials (Everling and Munoz, 2000). Based on these findings, we investigated which task-related modulation in oscillation power we observed was an indication of increased functional inhibition of saccade-generation mechanisms.

To identify which oscillatory signal corresponded to functional inhibition of saccade-related activity, we first contrasted preparatory power for correctly versus incorrectly performed AS trials (Fig. 5A). We found that FEF $8-16 \mathrm{~Hz}$ power was significantly stronger for correctly performed AS trials, whereas 42-60 $\mathrm{Hz}$ power was significantly stronger for incorrectly performed AS trials. We then follow up this result with a logistic regression to assess the trial-by-trial impact of preparatory oscillatory power on AS task performance. The independent variable was singletrial band-limited power (alpha:10-18 Hz, beta:18-38 Hz, gam- 

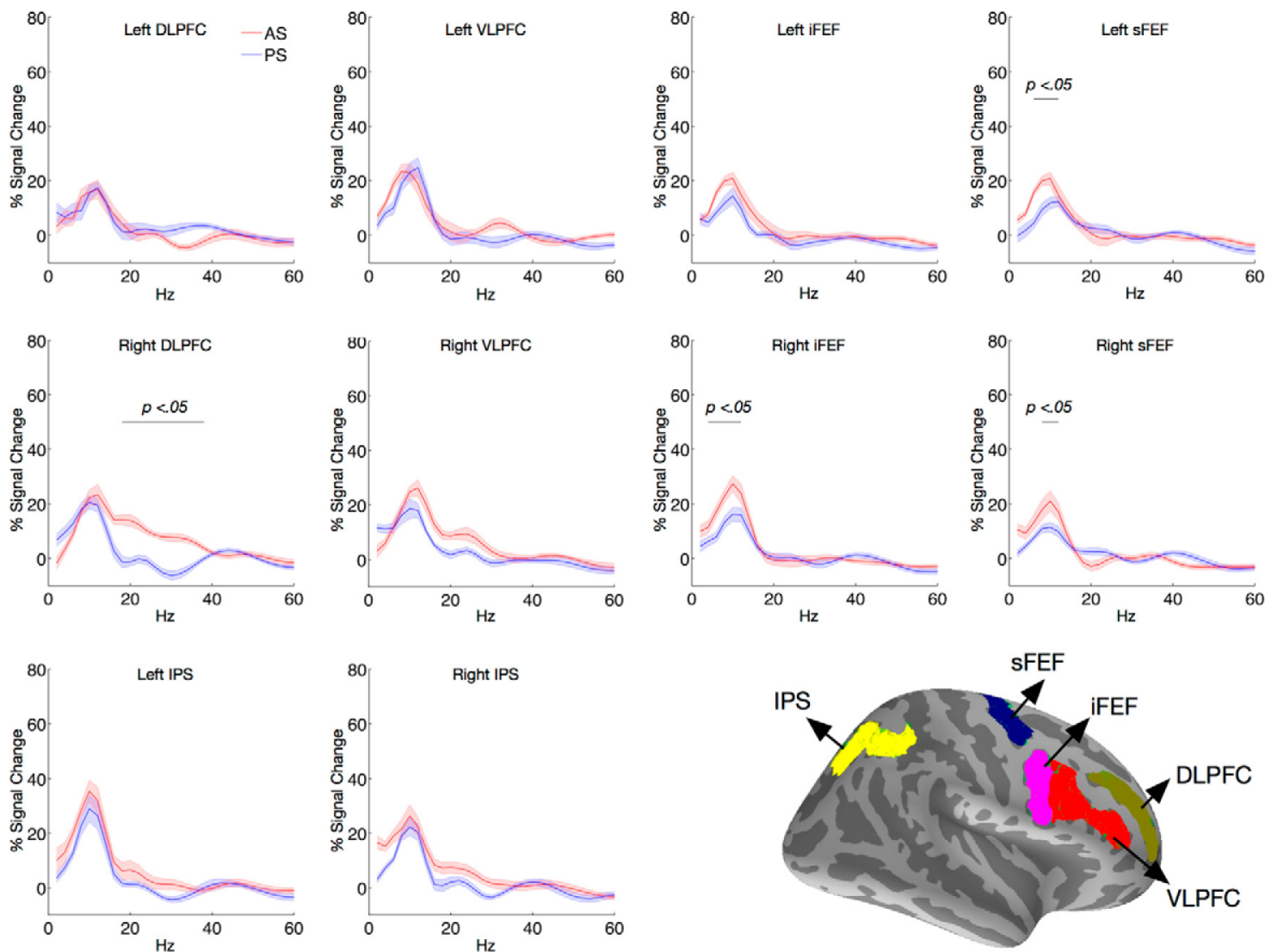

Figure 2. Averaged spectral power during the preparatory period for all ROls. The black horizontal bar indicates the spectral cluster that showed significant task modulation in spectral power. Bottom right depicts the anatomical masks used to define the ROls. Note that for each participant, ROls were created in their respective native surface space, thus the exact dipole location used for ROI definition varied across individuals. Shaded areas indicate $1 \mathrm{SE}$.

A

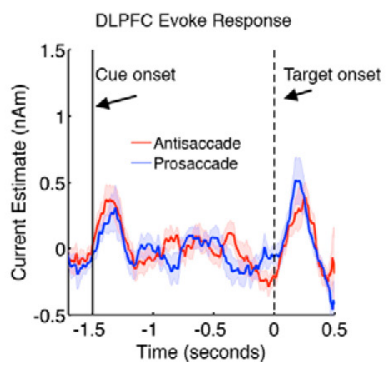

B

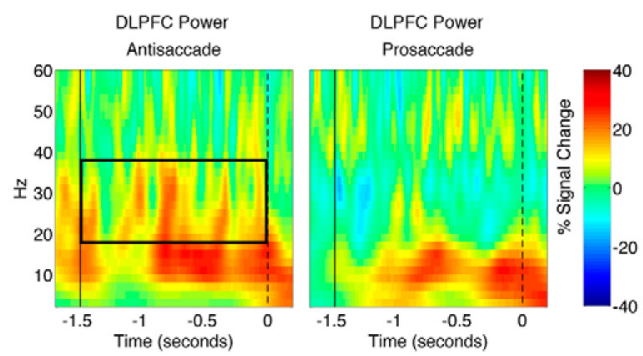

C

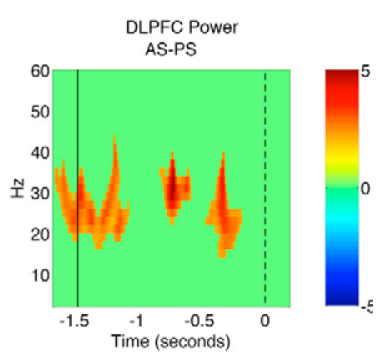

Figure 3. Temporal and spectral dynamics of DLPFC neural activity. $A$, Evoked responses for the AS and PS tasks in the right DLPFC. $B$, Time-frequency plot of DLPFC neural activity. Squared area indicates the spectrum that showed significant task modulation. C, Time-frequency clusters that showed significant task modulation (AS $>$ PS, randomization test $p<0.05$, cluster corrected). Shaded areas represent $1 \mathrm{SE}$.

ma: $40-60 \mathrm{~Hz}$ ) from each ROI averaged during the preparatory period. Specifically, we examined whether or not preparatory alpha-band power in the FEF was predictive of inhibiting saccades to the contralateral targets or ipsilateral targets. Results showed a positive association between preparatory alpha-band power in the FEF and the probability of performing a correct AS trial regardless of the target position (Fig. $5 B$; for contralateral targets: intercept $=1.57, \mathrm{~b}=0.0066, z=8.59, p<0.005$; for ipsilateral targets: intercept $=1.56, \mathrm{~b}=0.0047, z=8.16, p<$ $0.005)$. Given that participants could not predict saccade direction during the preparatory period, global suppression would need to be sustained in bilteral FEFs. No statistically significant associations between preparatory alpha-band power and AS task performance were found in other ROIs, and preparatory beta- band or gamma-band activities were not predictive of AS task performance on a trial-by-trial basis. We did not find a statistically significant association between trial-by-trial preparatory oscillatory power and saccade reaction time. We suspect this was because the determinants for saccade reaction time included not only preparatory oscillatory activity, but also sensorimotor transformation that occurred after the preparatory period. Preparatory power alone therefore did not have great predicative power of saccade reaction time.

If increased alpha-band power does reflect inhibition of saccade mechanism, it should decrease when participants are ready to make a saccade. To test this hypothesis, we aligned the timing of AS trials to time locked to the onset of the saccade, and analyzed time courses of alpha-band power before the onset of sac- 
A

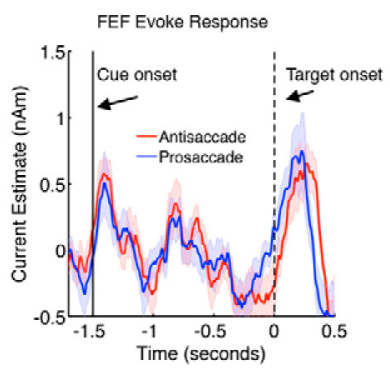

B

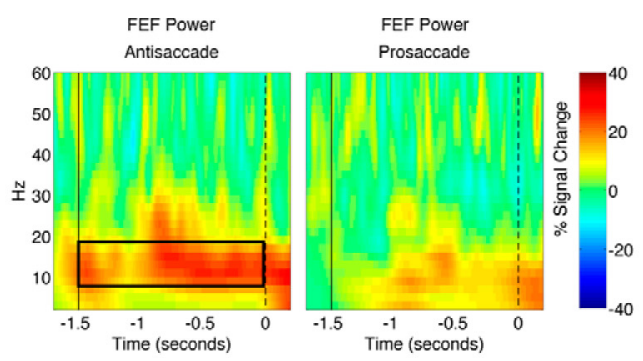

C

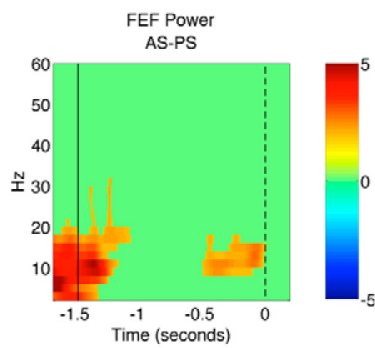

Figure 4. Temporal and spectral dynamics of FEF neural activity. $A$, Evoked responses for the AS and PS tasks in bilateral FEF. $B$, Time-frequency plot of FEF neural activity. Squared area indicates the spectrum that showed significant task modulation. C, Time-frequency clusters that that showed significant task modulation (AS $>$ PS, randomization test $p<0.05$, cluster corrected). Shaded areas represent $1 \mathrm{SE}$.

A

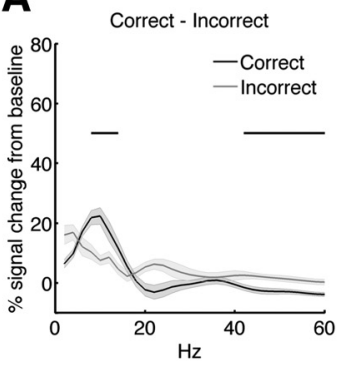

B

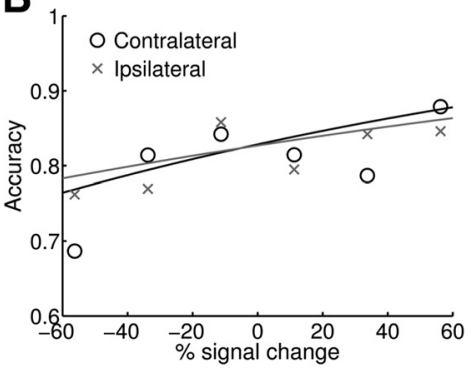

C

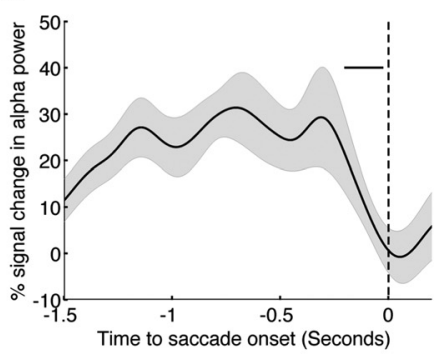

Figure 5. FEF alpha-band power indexes functional inhibition of saccade-related activity. $A$, Comparison of preparatory power between correctly performed AS trials and incorrectly performed AS trials. The black horizontal bar indicates the spectral cluster that showed significant performance modulation. $\boldsymbol{B}$, FEF alpha-band power during the preparatory period predicts the probability of successfully inhibiting reflexive saccades. " 0 " represents AS task performance to contralateral cues, black solid line is the fitted curve based on the logistic regression, and " $x$ " represents the AS task performance to ipsilateral cues, gray line is the fitted curve based on the logistic regression. C, FEF alpha-band power decreased from 204 to 24 ms before the onset of saccade (as indicate by the horizontal dark bar). Time 0 indicates the onset of saccades (vertical dash line). Shaded area represents $1 \mathrm{SE}$.

cades. We then performed a sliding window analysis to contrast alpha amplitudes between nearby time points, and to determine when and if alpha amplitude started to show significant decrease. Results indicated that FEF alpha-band power decreased from 204 to $24 \mathrm{~ms}$ before saccade onset (Fig. $5 \mathrm{C}$ ).

Inhibitory control enhances coupling between PFC beta-band activity and FEF alpha-band activity

Next, we investigated functional connectivity between DLPFC betaband and FEF alpha-band activities. Specifically, we tested for the possible role of lateral PFC as the source for top-down control signals that bias FEF activities and to exert functional inhibition of oculomotor processes. To test this hypothesis, we performed connectivity analyses on the frequency amplitude time courses, which has been previously shown to be effective in revealing connectivity patterns (Mazaheri et al., 2009; Nieuwenhuis et al., 2012). This approach was used because the DLPFC and the FEF showed robust power changes in different frequency bands. We first performed a cross-frequency functional connectivity analysis by correlating power amplitude time courses between ROIs and across frequencies to create crossfrequency coupling matrices. Results indicated significantly stronger coupling between DLPFC 10-26 Hz activity and FEF $8-18 \mathrm{~Hz}$ activity (Fig. 6A-C) for the AS task, when compared with the PS task. This frequency range overlapped with alpha- and beta-band power that showed significant task effects in our study, and suggests that inhibitory control enhances communication between task control (DLPFC beta-band activity) and functional inhibition (FEF alphaband activity) processes.

To determine whether DLPFC beta-band activity had a driving influence on FEF alpha-band activity, we then examined the relative timing between the DLPFC beta-band activity (restricting within $18-38 \mathrm{~Hz}$ ) and the FEF alpha-band activity (restricting within $10-18 \mathrm{~Hz}$ ) for the AS task. We found that peaks in DLPFC beta-band power preceded peaks in FEF alpha-band power (Fig. 6C). Lagged-correlation analysis of amplitude time courses further showed that the correlation between DLPFC beta-band activity and FEF alpha-band activity was greatest when the temporal lag was $\sim 80 \mathrm{~ms}$ (Fig. $6 D$ ), indicating that DLPFC beta-band activity led FEF alpha-band activity by $80 \mathrm{~ms}$. However, temporal precedence alone does not demonstrate causal interaction. To further quantify the causal influence between DLPFC and FEF, we performed GCA to test the strength of causal influence of DLPFC beta-band amplitude time courses on FEF alpha-band amplitude time courses and vice versa. In support of our hypothesis, we found that inhibitory control significantly increased causal influence from DLPFC beta-band activity $(18-38 \mathrm{~Hz})$ to FEF alpha-band activity $(10-18 \mathrm{~Hz})$, but not in the reverse direction (Fig. $6 E$; permutation test, $p<0.05$ ). No significant causal interactions were found for the PS task (permutation test, $p>0.05)$.

\section{Discussion}

Our findings indicate that DLPFC beta-band activity signals topdown control, and this signal initiates functional inhibition in the oculomotor system, demonstrating Granger causal influences over alpha-band activity in the FEF. Our research has two principal contributions. It provides novel evidence on how causal interaction between neocortical alpha and beta rhythms support proactive inhibitory control. Further, connecting our noninvasive human neuroimaging results with findings from electro- 
A

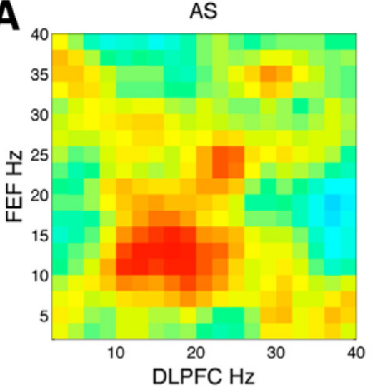

C

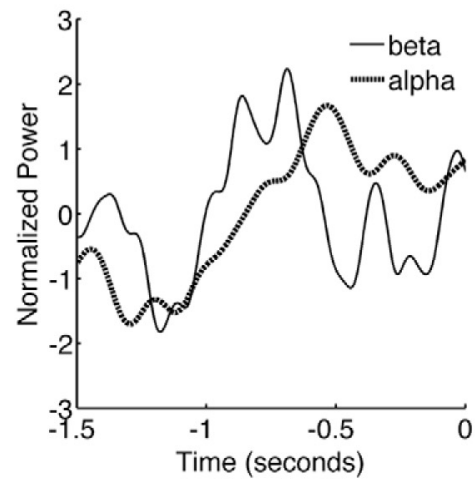

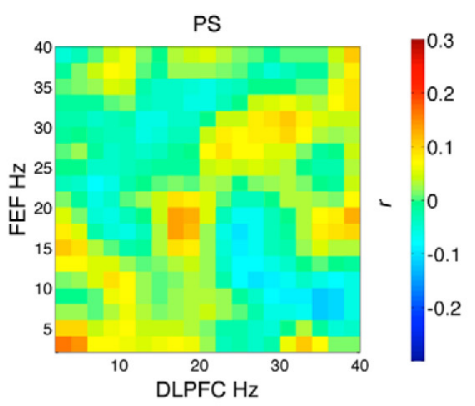

D

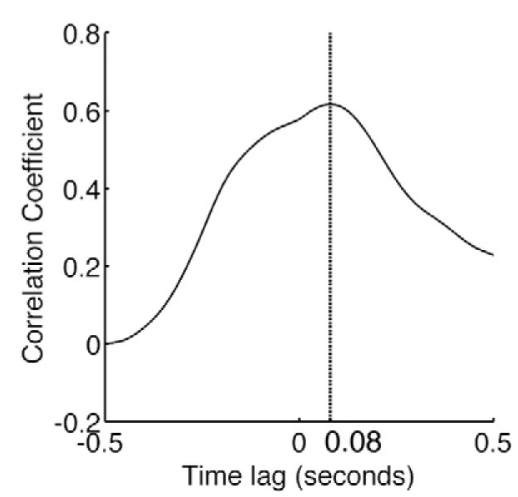

B
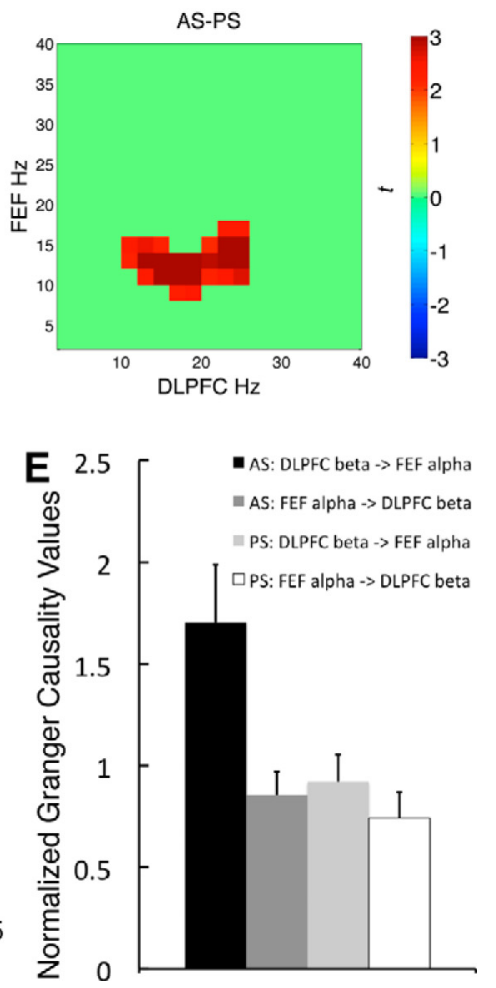

Figure 6. Functional coupling between DLPFC beta-band activity and FEF alpha-band activity. $\boldsymbol{A}$, Cross frequency amplitude coupling matrices between the DLPFC and the FEF. Color bar indicates the strength of functional connectivity (correlation coefficient, $r$ ). B, Spectral cluster that showed significantly stronger beta-alpha amplitude coupling between the DLPFC and the FEF for the AS task, when compared with the PS task. Color bar indicates the test statistic $(t)$. $C$, The timing of power amplitude time courses. Time courses were normalized by converting to $z$-scores to equate the mean amplitude and variance. $\boldsymbol{D}$, Lagged correlations between DLPFC beta-band amplitude and EFF alpha-band amplitude. The $x$-axis indicates the time lag of DLPFC beta-band activity leading FEF alpha-band activity. Maximum correlation was found when DLPFC led FEF by $80 \mathrm{~ms}$ (the dashed vertical line). $\boldsymbol{E}$, Granger causality values between DLPFC beta-band activity and FEF alpha-band activity. Error bar indicates $1 \mathrm{SE}$.

physiology studies and computation models (Everling et al., 1999; Everling and Munoz, 2000; Jones et al., 2009; VierlingClaassen et al., 2010; Haegens et al., 2011; Buschman et al., 2012), the causal association between beta- and alpha-band activity that we identified may provide a model of neocortical mechanism for top-down inhibitory control.

Nonhuman primate neurophysiology studies have found that saccade neurons in the FEF and the superior colliculus showed reduced spiking activity during the preparatory period for successful AS task performance (Everling et al., 1999; Everling and Munoz, 2000). This suggests that in contrast to reactive stopping motor actions in response to an external environmental cue (Aron, 2011), correct performance on the AS task requires proactive inhibition of saccade-related activity in the FEF even before the saccade target appears. Results from the current and previous studies strongly indicate that the enhanced preparatory FEF alpha-band power we found reflects such top-down inhibition signal. First, it has been shown that neuronal spike rate is negatively correlated with alpha-band power-when alpha-band power is high, neurons spike less frequently (Haegens et al., 2011). Further, we found that trial-by-trial preparatory alpha-band power in the FEF was positively correlated with AS performance. In addition, significant modulation in alpha-band power was found in the FEF but no other prefrontal and parietal regions, which demonstrates specificity in inhibiting saccade-related activity. These results support our interpretation that preparatory alpha-band activity in the FEF indexes functional inhibition of saccade-related activity - the stronger the inhibition (stronger trial-by-trial alpha-band power), the more likely reflexive saccades will be inhibited (better AS task performance). Nevertheless, to augment our correlational analyses, future studies that directly manipulate oscillatory activities are needed to establish causal links between alpha-band activity and functional inhibition of saccade-related activities, and to completely rule out confounding factors such as increased vigilance and response monitoring that are involved in executing the more difficult AS task. Similarly, MEG does not have the resolution to identify directionally tuned saccade neurons; the connection between our results and previous single-unit electrophysiology studies is an important topic for future research.

Previous animal and human studies have shown that spontaneous and intrinsic fluctuations in alpha-band activity influence stimulus discriminability and performances on motor inhibition (van Dijk et al., 2008; Mazaheri et al., 2009; Haegens et al., 2011; Hamm et al., 2012). As a result, spontaneous rhythmic changes in alpha-band activity have been suggested to reflect intrinsic fluctuations in cortical circuit's efficacy in processing information (Romei et al., 2008). Closely related to our study, one previous EEG study that used a cued saccade task found that alpha-band power measured from posterior scalp electrodes (above occipital and parietal lobes) decreased in preparation for a cued saccade target (Kelly et al., 2010). Using a rapid AS task with no preparatory period, another recent EEG study further demonstrated that this posterior alpha-band activity is rapid and flexible enough to reflect first the covert attention to the peripheral stimulus, and then the 
subsequent overt attention shift directs toward the opposite space (Belyusar et al., 2013). Results from these two studies and our own further suggest that in addition to intrinsic fluctuations, alpha-band activity could be influenced by task demands. By focusing on task-constrained modulations specifically in the FEF, we were able to extend these previous observations and identify task-driven alpha-band signals specific to top-down inhibitory control of a prepotent motor response tendency. Our results demonstrated that in addition to inhibiting sensory and spatial processes, alpha-band activity could be modulated by top-down cognitive factors for proactive inhibition of an anticipated response tendency.

Existing literature suggests that the lateral PFC is a source of top-down biasing signal that influences sensorimotor processes (Hwang et al., 2010; Johnston and Everling, 2011). We found that in response to the heightened control demand in AS trials, beta-band power increased in the right DLPFC during the preparatory period, and causally influenced FEF alphaband activity. These results suggest that DLPFC beta-band activity may be a signature of top-down signaling that increases functional inhibition in the FEF. Consistent with our findings, recent evidence suggests that lateral PFC beta-band oscillation encodes stimulus-response mapping (Buschman et al., 2012), and increases with cognitive effort when motor responses need to be inhibited (Swann et al., 2009). Note that the beta-band power frequency range we observed in DLPFC $(18-38 \mathrm{~Hz})$ is consistent with a previous study recorded directly from macaque Monkey's PFC, which they demonstrated that prefrontal neural assembles synchronize at the $19-40 \mathrm{~Hz}$ frequency range to encode task-relevant rules. Our results further indicated similar heightened beta-band activity in the VLPFC but did not reach statistical significance, possibly due to MEG's limitations in spatial resolution and relatively higher uncertainty in separating nearby sources.

We found that beta-band power increased in the right DLPFC but not the left DLPFC during the preparatory period. This PFC lateral effect is consistent with previous imaging studies demonstrating that the right PFC is involved in inhibiting motor responses(Aron et al., 2003; Rubia et al., 2003). It has also been found that compared with the PS task, the right DLPFC is more involved in AS task performance (Ford et al., 2005). A transcranial magnetic stimulation (TMS) study also found that when we used single-pulse TMS to interfere with the right DLPFC during the preparatory period, participants' AS performances suffered (Nyffeler et al., 2007). One study further found that patients with damage in the right VLPFC made more AS errors compared with patients with left VLPFC lesions (Hodgson et al., 2007). Given that no spatial information was present during the preparatory period, we found bilateral alpha-band modulation in the FEF during the preparatory period in preparation for inhibiting saccades to both hemifields (Fig. 2). However, the left sFEF but not the left iFEF showed significant alpha-band power modulation; this could be due to the higher uncertainty in MEG source localization.

Previous studies suggest that the IPS is involved in transforming the stimulus location vector into a saccade direction vector (Gottlieb and Goldberg, 1999; Zhang and Barash, 2000; Van Der Werf et al., 2008; i.e., sensorimotor transformation), a process required for AS task performance, and elevated IPS activity has been consistently found in other AS studies (Brown et al., 2007; Moon et al., 2007). Similarly, posterior alpha-band activity has been reported to reflect both covert and overt attention shifts that closely mimic this inversion process (Belyusar et al., 2013). In our paradigm the vector inversion process can only start once the target location has been revealed. This may account for why we did not observe significant task-related modulations in the IPS during the preparatory period, suggesting that the role of IPS may be more restricted to the response period. Alternatively, the attentional processes supported by the IPS (Criaud and Boulinguez, 2013) during the preparatory period may have been equivalent between AS and PS trials. However, existing findings on this issue are inconsistent (Connolly et al., 2002; Brown et al., 2007), and it is possible that the IPS is involved in other preparatory cognitive control processes for the AS task that were not evident in our study.

Spectral neurodynamics may further provide a window into the potential circuit mechanisms of inhibitory control. While the genesis of alpha rhythm is not well understood, studies suggest that alpha-band activity arises from corticothalamic interactions (Hughes and Crunelli, 2005; Jones et al., 2009; Bollimunta et al., 2011). Recent rodent model studies indicate that the thalamus innervates low-threshold spiking inhibitory neurons that could provide sustained inhibition on excitatory cells to reduce spiking outputs (Tan et al., 2008; Gentet et al., 2012). Computational models further suggest that low-threshold spiking interneurons could be involved in alpha rhythm genesis (Vierling-Claassen et al., 2010). Computational modeling designed specifically to study MEG current sources suggests that alpha-band activity may arise from two sources providing alpha rhythmic excitatory drive in antiphase to granular/infragranular and supragranular layers, respectively (Jones et al., 2009). The supragranular drive could come from higher order cortex, potentially DLPFC in line with our observations and existing anatomical data (Selemon and Goldman-Rakic, 1988), or from nonspecific thalamic nuclei that project strongly to supragranular layers (Jones, 2001). Although we found that DLPFC beta-band activity causally influenced FEF alpha-band activity, bivariate GCA analyses cannot rule out indirect causal interactions (Ding et al., 2006). Thalamocortical interactions could support the inhibition of saccade neurons that may be reflected in increases in alphaband activity.

Our results support accumulating evidence that prefrontal betaband activity may be a signature of top-down signaling. Beta-band oscillation has been found to be a prominent feature of frontalstriatal circuits (Courtemanche et al., 2003; Swann et al., 2009), and has been suggested to reflect cortical circuits that send outputs from deep layers of cortical columns (Wang, 2010), for example, to the striatum (Alexander et al., 1986). Through the striatum, the PFC could send signals to the globus pallidus and the substantia nigra that are composed of mainly GABAergic neurons to inhibit the thalamocortical oculomotor circuitry (Hikosaka et al., 2000). The subthalamic nucleus, which receives signals from the PFC, in turn inhibits the thalamocortical oculomotor circuitry (Nambu et al., 2002; Aron and Poldrack, 2006). The above models suggest that cortical inhibition relies on striatal-thalamic circuits, a model that is consistent with studies proposing that direct cortical-cortical projections are mostly excitatory in nature (Anderson et al., 2011; Munakata et al., 2011; Johnston et al., 2014). As such the DLPFC may not directly suppresses saccade neurons (Johnston et al., 2014); instead it may indirectly inhibit saccade-related activity through parallel cortical-subcortical interactions.

In summary, our study provides noninvasive, human neuroimaging evidence on how dynamics of oscillatory neural 
activities contribute to proactive inhibitory control. Our results are grounded in known neurophysiology findings, and can be further generalized as a framework for understanding the neural substrate for top-down cognitive control of targeted and selective inhibition: PFC beta-band activity signals top-down control, which further initiates selective functional inhibition of the effector and/or sensory system, as indicated by increases in alpha-band activity.

\section{References}

Akaishi R, Morishima Y, Rajeswaren VP, Aoki S, Sakai K (2010) Stimulation of the frontal eye field reveals persistent effective connectivity after controlled behavior. J Neurosci 30:4295-4305. CrossRef Medline

Alexander GE, DeLong MR, Strick PL (1986) Parallel organization of functionally segregated circuits linking basal ganglia and cortex. Annu Rev Neurosci 9:357-381. CrossRef Medline

Anderson JC, Kennedy H, Martin KA (2011) Pathways of attention: synaptic relationships of frontal eye field to V4, lateral intraparietal cortex, and area 46 in macaque monkey. J Neurosci 31:10872-10881. CrossRef Medline

Aron AR (2011) From reactive to proactive and selective control: developing a richer model for stopping inappropriate responses. Biol Psychiatry 69:e55-68. CrossRef Medline

Aron AR, Poldrack RA (2006) Cortical and subcortical contributions to stop signal response inhibition: role of the subthalamic nucleus. J Neurosci 26:2424-2433. CrossRef Medline

Aron AR, Fletcher PC, Bullmore ET, Sahakian BJ, Robbins TW (2003) Stopsignal inhibition disrupted by damage to right inferior frontal gyrus in humans. Nat Neurosci 6:115-116. CrossRef Medline

Aron AR, Robbins TW, Poldrack RA (2004) Inhibition and the right inferior frontal cortex. Trends Cogn Sci 8:170-177. CrossRef Medline

Aron AR, Behrens TE, Smith S, Frank MJ, Poldrack RA (2007) Triangulating a cognitive control network using diffusion-weighted magnetic resonance imaging (MRI) and functional MRI. J Neurosci 27:3743-3752. CrossRef Medline

Badre D, D'Esposito M (2009) Is the rostro-caudal axis of the frontal lobe hierarchical? Nat Rev Neurosci 10:659-669. CrossRef Medline

Banerjee S, Snyder AC, Molholm S, Foxe JJ (2011) Oscillatory alpha-band mechanisms and the deployment of spatial attention to anticipated auditory and visual target locations: supramodal or sensory-specific control mechanisms? J Neurosci 31:9923-9932. CrossRef Medline

Belyusar D, Snyder AC, Frey HP, Harwood MR, Wallman J, Foxe JJ (2013) Oscillatory alpha-band suppression mechanisms during the rapid attentional shifts required to perform an anti-saccade task. Neuroimage 65: 395-407. CrossRef Medline

Berman RA, Colby CL, Genovese CR, Voyvodic JT, Luna B, Thulborn KR, Sweeney JA (1999) Cortical networks subserving pursuit and saccadic eye movements in humans: an fMRI study. Hum Brain Mapp 8:209-225. CrossRef Medline

Bollimunta A, Mo J, Schroeder CE, Ding M (2011) Neuronal mechanisms and attentional modulation of corticothalamic alpha oscillations. J Neurosci 31:4935-4943. CrossRef Medline

Brown MR, Vilis T, Everling S (2007) Frontoparietal activation with preparation for antisaccades. J Neurophysiol 98 1751-1762.

Buschman TJ, Miller EK (2007) Top-down versus bottom-up control of attention in the prefrontal and posterior parietal cortices. Science 315: 1860-1862. CrossRef Medline

Buschman TJ, Denovellis EL, Diogo C, Bullock D, Miller EK (2012) Synchronous oscillatory neural ensembles for rules in the prefrontal cortex. Neuron 76:838-846. CrossRef Medline

Canolty RT, Knight RT (2010) The functional role of cross-frequency coupling. Trends Cogn Sci 14:506-515. CrossRef Medline

Chikazoe J, Konishi S, Asari T, Jimura K, Miyashita Y (2007) Activation of right inferior frontal gyrus during response inhibition across response modalities. J Cogn Neurosci 19:69-80. CrossRef Medline

Cohen MX (2011) It's about time. Front Hum Neurosci 5:2. CrossRef Medline

Connolly JD, Goodale MA, Menon RS, Munoz DP (2002) Human fMRI evidence for the neural correlates of preparatory set. Nat Neurosci 5:1345-1352. CrossRef Medline

Courtemanche R, Fujii N, Graybiel AM (2003) Synchronous, focally mod- ulated beta-band oscillations characterize local field potential activity in the striatum of awake behaving monkeys. J Neurosci 23:11741-11752. Medline

Criaud M, Boulinguez P (2013) Have we been asking the right questions when assessing response inhibition in go/no-go tasks with fMRI? A metaanalysis and critical review. Neurosci Biobehav Rev 37:11-23. CrossRef Medline

Curtis CE (2011) Testing animal models of human oculomotor control with neuroimaging. In: The Oxford handbook of eye movements (Liversedge SP, Gilchrist ID, Everling S, eds), pp 383-398. New York: Oxford UP.

Dale AM, Fischl B, Sereno MI (1999) Cortical surface-based analysis. I. Segmentation and surface reconstruction. Neuroimage 9:179-194. CrossRef Medline

Dale AM, Liu AK, Fischl BR, Buckner RL, Belliveau JW, Lewine JD, Halgren E (2000) Dynamic statistical parametric mapping: combining fMRI and MEG for high-resolution imaging of cortical activity. Neuron 26:55-67. CrossRef Medline

Delorme A, Makeig S (2004) EEGLAB: an open source toolbox for analysis of single-trial EEG dynamics including independent component analysis. J Neurosci Methods 134:9-21. CrossRef Medline

DeSouza J, Menon RS, Everling S (2003) Preparatory set associated with pro-saccades and anti-saccades in humans investigated with event-related fMRI. J Neurophysiol 89:1016-1023. Medline

Destrieux C, Fischl B, Dale A, Halgren E (2010) Automatic parcellation of human cortical gyri and sulci using standard anatomical nomenclature. Neuroimage 53:1-15. CrossRef Medline

Ding M, Chen Y, Bressler SL (2006) Granger causality: basic theory and application to neuroscience. In: Handbook of time series analysis: recent theoretical developments and applications (Schelter B, Winterhalder M, Timmer J, eds), p 437. Weinheim, Germany: Wiley-VCH.

Donner TH, Siegel M (2011) A framework for local cortical oscillation patterns. Trends Cogn Sci 15:191-199. CrossRef Medline

Everling S, Munoz DP (2000) Neuronal correlates for preparatory set associated with pro-saccades and anti-saccades in the primate frontal eye field. J Neurosci 20:387-400. Medline

Everling S, Dorris MC, Klein RM, Munoz DP (1999) Role of primate superior colliculus in preparation and execution of anti-saccades and prosaccades. J Neurosci 19:2740-2754. Medline

Fischl B, Sereno MI, Dale AM (1999) Cortical surface-based analysis. II. Inflation, flattening, and a surface-based coordinate system. Neuroimage 9:195-207. CrossRef Medline

Ford KA, Goltz HC, Brown MR, Everling S (2005) Neural processes associated with antisaccade task performance investigated with event-related FMRI. J Neurophysiol 94:429-440. CrossRef Medline

Foxe JJ, Simpson GV, Ahlfors SP (1998) Parieto-occipital approximately 10 $\mathrm{Hz}$ activity reflects anticipatory state of visual attention mechanisms. Neuroreport 9:3929-3933. CrossRef Medline

Gentet LJ, Kremer Y, Taniguchi H, Huang ZJ, Staiger JF, Petersen CC (2012) Unique functional properties of somatostatin-expressing GABAergic neurons in mouse barrel cortex. Nat Neurosci 15:607-612. CrossRef Medline

Ghuman AS, McDaniel JR, Martin A (2011) A wavelet-based method for measuring the oscillatory dynamics of resting-state functional connectivity in MEG. Neuroimage 56:69-77. CrossRef Medline

Gottlieb J, Goldberg ME (1999) Activity of neurons in the lateral intraparietal area of the monkey during an antisaccade task. Nat Neurosci 2:906912. CrossRef Medline

Grosbras MH, Lobel E, Van de Moortele PF, LeBihan D, Berthoz A (1999) An anatomical landmark for the supplementary eye fields in human revealed with functional magnetic resonance imaging. Cereb Cortex 9:705711. CrossRef Medline

Gross J, Baillet S, Barnes GR, Henson RN, Hillebrand A, Jensen O, Jerbi K, Litvak V, Maess B, Oostenveld R, Parkkonen L, Taylor JR, van Wassenhove V, Wibral M, Schoffelen JM (2013) Good practice for conducting and reporting MEG research. Neuroimage 65:349-363. CrossRef Medline

Haegens S, Nácher V, Luna R, Romo R, Jensen O (2011) Alpha-Oscillations in the monkey sensorimotor network influence discrimination performance by rhythmical inhibition of neuronal spiking. Proc Natl Acad Sci U S A 108:19377-19382. CrossRef Medline

Hallett PE (1978) Primary and secondary saccades to goals defined by instructions. Vision Res 18:1279-1296. CrossRef Medline 
Hamalainen MS (2010) MNE software user's guide. Charlestown, MA: Massachusetts General Hospital.

Hämäläinen MS, Sarvas J (1989) Realistic conductivity geometry model of the human head for interpretation of neuromagnetic data. IEEE Trans Biomed Eng 36:165-171. CrossRef Medline

Hamalainen MS, Lin FH, Mosher JC (2010) Anatomically and functionally constrained minimum-norm estimates. In: MEG: an introduction to methods (Hansen PC, Kringelbach ML, Salmelin R, eds), pp 186-215. New York: Oxford UP.

Hamm JP, Dyckman KA, McDowell JE, Clementz BA (2012) Pre-cue fronto-occipital alpha phase and distributed cortical oscillations predict failures of cognitive control. J Neurosci 32:7034-7041. CrossRef Medline

Hikosaka O, Takikawa Y, Kawagoe R (2000) Role of the basal ganglia in the control of purposive saccadic eye movements. Physiol Rev 80:953-978. Medline

Hodgson T, Chamberlain M, Parris B, James M, Gutowski N, Husain M, Kennard C (2007) The role of the ventrolateral frontal cortex in inhibitory oculomotor control. Brain 130:1525-1537. CrossRef Medline

Hughes SW, Crunelli V (2005) Thalamic mechanisms of EEG alpha rhythms and their pathological implications. Neuroscientist 11:357-372. CrossRef Medline

Hwang K, Velanova K, Luna B (2010) Strengthening of top-down frontal cognitive control networks underlying the development of inhibitory control: a functional magnetic resonance imaging effective connectivity study. J Neurosci 30:15535-15545. CrossRef Medline

Jensen O, Mazaheri A (2010) Shaping functional architecture by oscillatory alpha activity: gating by inhibition. Front Hum Neurosci 4:186. CrossRef Medline

Johnston K, Everling S (2011) Frontal cortex and saccadic control. In: The Oxford handbook of eye movements (Liversedge SP, Gilchrist ID, Everling S, eds), pp 279-302. New York: Oxford UP.

Johnston K, Koval MJ, Lomber SG, Everling S (2014) Macaque dorsolateral prefrontal cortex does not suppress saccade-related activity in the superior colliculus. Cereb Cortex 24:1373-1388. CrossRef Medline

Jones EG (2001) The thalamic matrix and thalamocortical synchrony. Trends Neurosci 24:595-601. CrossRef Medline

Jones SR, Pritchett DL, Sikora MA, Stufflebeam SM, Hämäläinen M, Moore CI (2009) Quantitative analysis and biophysically realistic neural modeling of the MEG mu rhythm: rhythmogenesis and modulation of sensory-evoked responses. J Neurophysiol 102:3554-3572. CrossRef Medline

Jones SR, Kerr CE, Wan Q, Pritchett DL, Hämäläinen M, Moore CI (2010) Cued spatial attention drives functionally relevant modulation of the mu rhythm in primary somatosensory cortex. J Neurosci 30:13760-13765. CrossRef Medline

Kelly SP, Foxe JJ, Newman G, Edelman JA (2010) Prepare for conflict: EEG correlates of the anticipation of target competition during overt and covert shifts of visual attention. Eur J Neurosci 31:1690-1700. CrossRef Medline

Klimesch W, Sauseng P, Hanslmayr S (2007) EEG alpha oscillations: the inhibition-timing hypothesis. Brain Res Rev 53:63-88. CrossRef Medline

Koval MJ, Lomber SG, Everling S (2011) Prefrontal cortex deactivation in macaques alters activity in the superior colliculus and impairs voluntary control of saccades. J Neurosci 31:8659-8668. CrossRef Medline

Lee AK, Hämäläinen MS, Dyckman KA, Barton JJ, Manoach DS (2011) Saccadic preparation in the frontal eye field is modulated by distinct trial history effects as revealed by magnetoencephalography. Cereb Cortex 21: 245-253. CrossRef Medline

Levy BJ, Wagner AD (2011) Cognitive control and right ventrolateral prefrontal cortex: reflexive reorienting, motor inhibition, and action updating. Ann N Y Acad Sci 1224:40-62. CrossRef Medline

Luna B, Thulborn KR, Strojwas MH, McCurtain BJ, Berman RA, Genovese CR, Sweeney JA (1998) Dorsal cortical regions subserving visuallyguided saccades in humans: an fMRI study. Cereb Cortex 8:40-47. CrossRef Medline

Maris E, Oostenveld R (2007) Nonparametric statistical testing of EEG- and MEG-data. J Neurosci Methods 164:177-190. CrossRef Medline

Mazaheri A, Nieuwenhuis IL, van Dijk H, Jensen O (2009) Prestimulus alpha and mu activity predicts failure to inhibit motor responses. Hum Brain Mapp 30:1791-1800. CrossRef Medline

Menon V, Adleman NE, White CD, Glover GH, Reiss AL (2001) Error- related brain activation during a Go/NoGo response inhibition task. Hum Brain Mapp 12:131-143. CrossRef Medline

Moon SY, Barton JJ, Mikulski S, Polli FE, Cain MS, Vangel M, Hämäläinen MS, Manoach DS (2007) Where left becomes right: a magnetoencephalographic study of sensorimotor transformation for antisaccades. Neuroimage 36:1313-1323. CrossRef Medline

Munakata Y, Herd SA, Chatham CH, Depue BE, Banich MT, O’Reilly RC (2011) A unified framework for inhibitory control. Trends Cogn Sci 15: 453-459. CrossRef Medline

Munoz DP, Everling S (2004) Look away: the anti-saccade task and the voluntary control of eye movement. Nat Rev Neurosci 5:218-228. CrossRef Medline

Nambu A, Tokuno H, Takada M (2002) Functional significance of the cortico-subthalamo-pallidal 'hyperdirect' pathway. Neurosci Res 43:111117. CrossRef Medline

Nenonen J, Nurminen J, Kičić D, Bikmullina R, Lioumis P, Jousmäki V, Taulu S, Parkkonen L, Putaala M, Kähkönen S (2012) Validation of head movement correction and spatiotemporal signal space separation in magnetoencephalography. Clin Neurophysiol 123:2180-2191. CrossRef Medline

Nieuwenhuis IL, Takashima A, Oostenveld R, McNaughton BL, Fernández G, Jensen O (2012) The neocortical network representing associative memory reorganizes with time in a process engaging the anterior temporal lobe. Cereb Cortex 22:2622-2633. CrossRef Medline

Nyffeler T, Müri R, Bucher-Ottiger Y, Pierrot-Deseilligny C, Gaymard B, Rivaud-Pechoux S (2007) Inhibitory control of the human dorsolateral prefrontal cortex during the anti-saccade paradigm - a transcranial magnetic stimulation study. Eur J Neurosci 26:1381-1385. CrossRef Medline

Oostenveld R, Fries P, Maris E, Schoffelen JM (2011) FieldTrip: open source software for advanced analysis of MEG, EEG, and invasive electrophysiological data. Comput Intell Neurosci 2011:156869. CrossRef Medline

Romei V, Brodbeck V, Michel C, Amedi A, Pascual-Leone A, Thut G (2008) Spontaneous fluctuations in posterior alpha-band EEG activity reflect variability in excitability of human visual areas. Cereb Cortex 18:2010 2018. CrossRef Medline

Rubia K, Smith AB, Brammer MJ, Taylor E (2003) Right inferior prefrontal cortex mediates response inhibition while mesial prefrontal cortex is responsible for error detection. Neuroimage 20:351-358. CrossRef Medline

Schiller PH, Sandell JH, Maunsell JH (1987) The effect of frontal eye field and superior colliculus lesions on saccadic latencies in the rhesus monkey. J Neurophysiol 57:1033-1049. Medline

Schoffelen JM, Gross J (2009) Source connectivity analysis with MEG and EEG. Hum Brain Mapp 30:1857-1865. CrossRef Medline

Selemon LD, Goldman-Rakic PS (1988) Common cortical and subcortical targets of the dorsolateral prefrontal and posterior parietal cortices in the rhesus monkey: evidence for a distributed neural network subserving spatially guided behavior. J Neurosci 8:4049-4068. Medline

Seth AK (2010) A MATLAB toolbox for Granger causal connectivity analysis. J Neurosci Methods 186:262-273. CrossRef Medline

Siegel M, Donner TH, Engel AK (2012) Spectral fingerprints of largescale neuronal interactions. Nat Rev Neurosci 13:121-134. CrossRef Medline

Swann N, Tandon N, Canolty R, Ellmore TM, McEvoy LK, Dreyer S, DiSano M, Aron AR (2009) Intracranial EEG reveals a time- and frequencyspecific role for the right inferior frontal gyrus and primary motor cortex in stopping initiated responses. J Neurosci 29:12675-12685. CrossRef Medline

Tallon-Baudry C, Bertrand O, Delpuech C, Permier J (1997) Oscillatory gamma-band $(30-70 \mathrm{~Hz})$ activity induced by a visual search task in humans. J Neurosci 17:722-734. Medline

Tan Z, Hu H, Huang ZJ, Agmon A (2008) Robust but delayed thalamocortical activation of dendritic-targeting inhibitory interneurons. Proc Natl Acad Sci U S A 105:2187-2192. CrossRef Medline

Taulu S, Hari R (2009) Removal of magnetoencephalographic artifacts with temporal signal-space separation: demonstration with single-trial auditory-evoked responses. Hum Brain Mapp 30:1524-1534. CrossRef Medline

Taulu S, Kajola M, Simola J (2004) Suppression of interference and artifacts by the Signal Space Separation Method. Brain Topogr 16:269-275. Medline 
Van Der Werf J, Jensen O, Fries P, Medendorp WP (2008) Gamma-band activity in human posterior parietal cortex encodes the motor goal during delayed prosaccades and antisaccades. J Neurosci 28:8397-8405. CrossRef Medline

van Dijk H, Schoffelen JM, Oostenveld R, Jensen O (2008) Prestimulus oscillatory activity in the alpha band predicts visual discrimination ability. J Neurosci 28:1816-1823. CrossRef Medline

Vierling-Claassen D, Cardin JA, Moore CI, Jones SR (2010) Computational modeling of distinct neocortical oscillations driven by cell-type selective optogenetic drive: separable resonant circuits controlled by lowthreshold spiking and fast-spiking interneurons. Front Hum Neurosci 4:198. CrossRef Medline
Wang XJ (2010) Neurophysiological and computational principles of cortical rhythms in cognition. Physiol Rev 90:1195-1268. CrossRef Medline

Wehner DT, Hämäläinen M, Mody M, Ahlfors SP (2008) Head movements of children in MEG: quantification, effects on source estimation, and compensation. Neuroimage 40:541-550. CrossRef Medline

Worden MS, Foxe JJ, Wang N, Simpson GV (2000) Anticipatory biasing of visuospatial attention indexed by retinotopically specific alpha-band electroencephalography increases over occipital cortex. J Neurosci 20:RC63. Medline

Zhang M, Barash S (2000) Neuronal switching of sensorimotor transformations for antisaccades. Nature 408:971-975. CrossRef Medline 